\title{
Addressing editor(ial) malpractice in scientific journals
}

\author{
Steven J. Cooke and Nicolas W.R. Lapointe
}

Steven J. Cooke (Steven_Cooke@carleton.ca), Fish Ecology and Conservation Physiology Laboratory, Institute of Environmental Science and Department of Biology, Carleton University, Ottawa, ON, Canada K1S 5B6

Nicolas W.R. Lapointe (nlapointe@gmail.com), Fish Ecology and Conservation Physiology Laboratory, Institute of Environmental Science and Department of Biology, Carleton University, Ottawa, ON, Canada K1S 5B6

\section{Introduction}

Editor (noun): A person who is in charge of and determines the final content of a newspaper, magazine, or multi-author book (author addition... and scientific journal). (Oxford Dictionary)

In the scientific peer-review system, editors serve a critical role (Bornmann 2011). Essentially they are the gatekeepers for scientific integrity (Crane 1967; Rolland 2009). They have final say with respect to editorial decisions (Roediger 1987; Newton 2010), and these individuals also set policy regarding peer review and the strategic vision for their respective journals. Editors play an important role in detecting and preventing scientific misconduct (Marusic et al. 2007), and ensuring high ethical standards (Shamoo 1994). Editors work at the interface between authors, referees, and publishers (including some sponsoring organizations) thereby orchestrating the entire peer-review process (Roediger 1987) - a processes that is constantly being examined and evaluated (Smith 2006; Aarssen and Lortie 2009, 2010; Aarssen 2012) despite being a fundamental part of science since the 1660's (Bishop 1984). Considering that in the scientific community the majority of editorial positions are voluntary or at best have a modest stipend, one might question why anyone would ever wish to take on such a position given the demands that it puts on one's time (e.g., see Zanna 1992). We have the utmost respect for those that do serve in such roles. Indeed, science and the scientific community depend on them and society, the economy, human health, and the environment benefit from their service as they facilitate the transformation of scientific findings into scientific knowledge (Gilbert 1976; Roediger 1987; Robertson 2009).

As authors, referees, associate editors/subject editors/science editors/book editors, members of several editorial advisory boards, and chair of a publication overview committee for a professional society (Cooke), we have interacted with many different editors and note extensive variation in their behaviour. As aspiring editors with strong interests in ensuring the integrity of the peer-review process (see Schäfer et al. 2011), we value what we have learned from these experiences - as much from the bad experiences as from the good. In most instances, our papers have benefited from the dedication of editors committed to identifying problems and improving our scientific communication. However, in various capacities we have also observed or been subject to a variety of editorial actions that we feel are inconsistent with responsible editorial practice-herein what we will call "editor(ial) malpractice" (as per Ray 2002). Some have gone so far as to characterize the relationship between editor and author as "editorial power and authorial suffering" (Roth 2002). Rather than simply complaining to colleagues in hallways, we believe that there is merit in exploring some of these experiences here.

It is our opinion that some of the actions (or inactions) of editors actually burden the peer-review process, have the potential to alienate early-career researchers (Schäfer et al. 2011), and in some cases do not lead to the highest of scientific standards (Godlee 
2004). It could be argued that everything an editor does is in the service of their journal and the scientific community; however, we will argue here that editorial actions can certainly be imperfect and there is room for improvement, both in terms of changes that can be made by individual editors as well as to the institutional structures within which they work. We are not the first to critique editors; indeed, Crandall (1986) goes so far as to offer sympathies to authors. Of course our hope here is that our thoughts will lead to open discourse and change. Beyond identifying these issues, we also postulate as to why they arise and what could be done to address them (See Table 1). In doing so we primarily consider the role of editors but where appropriate we also consider that of authors and referees. As we both become more involved with scientific editing, we are learning about expectations and identifying useful resources, which we will share here. Where possible, we focus on issues relevant to the disciplines of ecology and evolution but note that we rely heavily on information from a variety of disciplines, in particular medicine, and in general we suspect that these issues persist throughout the scientific publishing world. We want to be clear that this is not a witch hunt or a matter of being ungrateful or spiteful. Indeed, we would surmise that most responsible scientific editors would find the practices described below as problematic; however, the beauty of IEE as an outlet is that criticisms or other perspectives are encouraged!

\section{Examples of Editor Malpractice}

Overzealous screening of papers prior to peer reviewThe premise of pre-screening papers prior to soliciting referees is an important one. Based on an initial examination, editors are able to assess the overall quality (albeit sometimes in a superficial way) and to determine if the paper is a good fit with the journal aims and strategic directions. This improves efficiency in the peer-review process, and can be of benefit to both the journal and author when topics are a poor fit, or the quality of the paper is clearly substandard. Some highend journals may additionally carry expectations of novelty and general interest for a paper to be considered. The most common rationale provided for prereview rejection is that there is simply insufficient space to publish all papers (Campanario 1996; Aarssen 2012) and that the work is not of great enough interest to the journal. This of course does not burden peer reviewers and enables the paper to be reformatted and resubmitted to an alternative journal with minimal delay. There are certainly instances where fit is not ideal and pre-review rejection is to be expected.

Despite the advantages of pre-screening and rejecting inappropriate papers, it is our opinion that pre-screening is at times overzealous, with rejections based on weak arguments (see Aarssen 2012; Wardle 2012). As an author, this is certainly annoying given that it takes considerable time to reformat papers. It is our opinion that, in recent years, more manuscripts are being rejected without review (see Aarssen 2012). Given that many journals are online only, the excuse that journal space is limited seems moot (we do recognize there are processing costs for every paper) so rejections are likely driven by a quest for increased impact factor (Krell 2010) — a process Aarssen (2012) calls "gate-keeping elitism" motivated by self-serving goals. With journal proliferation there seems to be the perception that there are many other outlets for work and that by pre-screening (i.e., rejecting) it is possible to elevate the quality of content in a given journal; however, Wardle (2012) demonstrates that this approach fails for all but the most high-profile generalist/multidisciplinary journals. In ecology and evolution, Wardle (2012) noted "the longstanding assumption that rejecting a large proportion of submissions will result in a higher average quality of published papers that garner a larger numbers of citations and boost the journal's impact factor, is largely unsupported from this [sic. his] analysis".

The rationale for rejection is not obvious in many cases, particularly when papers seem to fit journal aims perfectly or are consistent with other matter published recently by the journal. As authors, when we try to select what we believe to be the best fit for a journal (in terms of content and readership) for a given paper, we seem to be increasingly off the mark. If journals are going to reject a large proportion of papers based on fit then the aims of journals need to be refined to reflect these policies. Some editors revisit strategic directions for a journal on a regular basis, yet rarely share these directions openly with those submitting papers. Perhaps more explicit aims and scopes would better enable authors to target their articles to the right journal in the first instance. There is also often a disconnect between editors' (and editorial board's) perspectives on key topics for a journal versus those perceived by readers and authors (see Justice et al. 1994; Lundberg et al. 1998). In other words, editors may screen for papers that would make valuable contributions (Wardle 2012) and that the scientific community would desire. It is worth noting that in some cases the overzealous rejection is driven by publishers rather than editors (Aarssen 2012), but in general it is our belief that they co-conspire and authors simply accept it.

Rejection based on fit after peer review-The rejection of papers after peer review based on journal fit is corollary to overzealous pre-screening, and is certainly a more egregious practice. This outcome typically means that an editor failed to read and screen the paper properly prior to review and left this task to the referees. Such actions place an unnecessary burden on the peer-review 


\begin{tabular}{|c|c|c|}
\hline Type & $\begin{array}{l}\text { Description/Reason for Occurrence and } \\
\text { Consequences }\end{array}$ & e \\
\hline $\begin{array}{l}\text { Overzealous pre- } \\
\text { screening prior to } \\
\text { review }\end{array}$ & $\begin{array}{l}\text { Editors reject papers that seemingly fit the scope of the } \\
\text { journal; } \\
\text { Rejections may occur in an attempt to improve impact } \\
\text { factor. }\end{array}$ & $\begin{array}{l}\text { Acknowledge that rejecting a large proportion of papers prior to review does not increase } \\
\text { impact factor; } \\
\text { Provide clearer description of journal aims and scope in guides to authors, and follow these } \\
\text { guidelines during pre-screening; } \\
\text { Journal scope should be updated regularly and include specific priority topics identified by the } \\
\text { editorial board. }\end{array}$ \\
\hline $\begin{array}{l}\text { Rejection based on } \\
\text { lack of fit, after } \\
\text { peer-review }\end{array}$ & $\begin{array}{l}\text { Editor did not assess paper properly prior to review; } \\
\text { Unduly burdens referees. }\end{array}$ & $\begin{array}{l}\text { Thoroughly consider manuscripts before contacting referees (i.e., pre-screen); } \\
\text { Do not rely on referees to determine if the paper fits the remit of the journal. }\end{array}$ \\
\hline $\begin{array}{l}\text { Inability to secure } \\
\text { peer-reviews }\end{array}$ & $\begin{array}{l}\text { Papers remain in review for extended periods because of } \\
\text { a failure to identify reviewers; } \\
\text { Papers rejected without review solely on this basis; } \\
\text { Unduly delays publication. }\end{array}$ & $\begin{array}{l}\text { Request additional referees from authors or referees that decline; } \\
\text { Identify referees from works cited in the manuscript or from external search engines; } \\
\text { Consider alternate referees with different backgrounds; } \\
\text { Be persistent in securing referees, including the use of phone calls and personalized emails } \\
\text { (rather than computer generated form letters); } \\
\text { Consider recruiting referee reports from early career researchers (including students and post- } \\
\text { docs). }\end{array}$ \\
\hline Unnecessary drama & $\begin{array}{l}\text { Rejection/Revision letters are often strongly worded; } \\
\text { Can incorrectly give the impression of an unfavourable } \\
\text { review or rejection; } \\
\text { Is de-motivating, especially for early-career researchers; } \\
\text { Can contradict reviews. }\end{array}$ & $\begin{array}{l}\text { Avoid reliance on form letters; } \\
\text { Describe revisions as minor when that is the case; } \\
\text { Do not force authors to have to interpret vague language or to read between the lines (i.e., be } \\
\text { clear and direct); } \\
\text { Avoid condescending and rejective language. }\end{array}$ \\
\hline $\begin{array}{l}\text { Failure to read } \\
\text { paper }\end{array}$ & $\begin{array}{l}\text { Paper and/or reviews were not read in detail by the } \\
\text { editor; } \\
\text { Comments in response to authors not relevant to paper or } \\
\text { reviews. }\end{array}$ & $\begin{array}{l}\text { Read thoroughly at submission to evaluate suitability; } \\
\text { Read again after reviews are received and form an opinion which integrates one's own } \\
\text { knowledge along with that of the referees. }\end{array}$ \\
\hline $\begin{array}{l}\text { Excessive or lack } \\
\text { of editing }\end{array}$ & $\begin{array}{l}\text { Editors impose their personal writing style on the } \\
\text { document; } \\
\text { Alternatively, editors may not provide any detailed } \\
\text { comments beyond concerns identified by reviewers. }\end{array}$ & $\begin{array}{l}\text { Recognize individual writing styles may differ and instead focus on clarity; } \\
\text { There should be an expectation of general (and ideally specific) comments provided by the } \\
\text { editor demonstrating that they have read and understood the paper and the referee reports. }\end{array}$ \\
\hline $\begin{array}{l}\text { Inability to act and } \\
\text { think } \\
\text { independently }\end{array}$ & $\begin{array}{l}\text { Editors fail to provide their own perspective or to } \\
\text { critically evaluate the reviews provided by referees which } \\
\text { can lead to erroneous editorial decisions; } \\
\text { Inability to assess author responses to even the most } \\
\text { minor of revisions without seeking external referee input. }\end{array}$ & $\begin{array}{l}\text { Editorial decisions should never simply refer the author to the comments provided by the } \\
\text { referee; } \\
\text { Editors should provide guidance to authors on which referee points (major ones) to focus on or } \\
\text { ignore; } \\
\text { Editors should have sufficient topical expertise such that they are able to evaluate minor to } \\
\text { modest revisions without having to send for re-review or seek additional referee input. }\end{array}$ \\
\hline $\begin{array}{l}\text { Reliance on form } \\
\text { letters }\end{array}$ & $\begin{array}{l}\text { Although "easy" for editors, form letters fail to } \\
\text { provide authors with relevant input. }\end{array}$ & $\begin{array}{l}\text { Letters should summarize the basis for their decision (including evidence to support } \\
\text { editorial decision). }\end{array}$ \\
\hline
\end{tabular}


system and delay the potential publication of the paper elsewhere, ultimately delay the advancement of knowledge. In our opinion, it is not the job of the referee to evaluate journal fit. That said, as reviewers we increasingly find ourselves emphasizing that papers are a good fit for journals because we disagree with journal fit being used as a rejection criteria after review. We only suggest that papers are not an acceptable fit in the worst cases. Nothing is more frustrating than to have multiple positive reviews that suggest that a paper may fit better with a different outlet. The wasted effort in terms of referees is tremendous. If this was the outcome for just 1 in 5 reviews, then we would require at least $20 \%$ more referees, a commodity rarely found in surplus nor an efficient way to conduct peer review.

Inability to secure peer reviews-Once an editor has deemed that a paper is appropriate to be sent to peer review, their next task is typically to identify and secure referees within a reasonable period of time. There are a variety of strategies for doing so including having authors identify possible referees, selecting referees from works cited in the manuscript, use of external searches (e.g., Web of Science; note that many journalmanagement software platforms have these built into their structure), and use of databases maintained by a given journal. In addition, when a potential referee declines they may be prompted to provide alternative referees. On rare occasions, papers are rejected based on an inability of the editors to secure referees (Cooke has experienced this as an author on three occasions, once 10 months following initial submission). As an editor, I find this nearly impossible to believe. One needs to be persistent and creative in identifying and securing referees. I have been telephoned by editors asking if I would review a paper for which they were having difficulty finding referees. As an editor desperate for another referee, I have called in favours from personal acquaintances, begging them to review a paper for which they have the expertise. When I am too busy to serve as a reviewer, I have been asked if I could recommend an early career scientist (e.g., recent graduates, post-docs) to participate in the review process (see Donaldson et al. 2010). I am familiar with reviewer fatigue both as a reviewer and editor; however, I think that much of this fatigue is related to a failure to expand the network of referees beyond the most active authors. As an editor I like to secure reviews from referees with different types of experience and at different stages of their career. The challenge is how to identify "lesserknown" (i.e., lesser-published) scientists that would be quite capable of providing an appropriate review (Schäfer et al. 2011). It is easy for referees to dismiss electronic invites; thus, increased use of personal communications may be needed. It is also reasonable to ask authors for the names of additional referees, especially prior to rejecting a paper because of an inability to secure referees.

Unnecessary drama-There is a tendency for editors to be overly and unnecessarily dramatic with delivery of editorial decisions. For those whose first language is not English this can be confusing, and for early career researchers, it can be devastating. Editors should not leave it to the authors to read between the lines of an editorial decision. Even when a paper receives two virtually glowing reviews and the changes to be made are minor, the letter from the editor seems to convey that it needs a major re-write. Likewise, requests for major revisions are often worded as though the paper is being rejected (Schäfer et al. 2011). In some ways this issue relates to a reliance on form letters, which can be condescending, and frequently contradict reviews and even editorial comments (see below). The editor should provide clear and specific advice without unnecessary drama. In particular, there seems to be a massive reluctance to use the "minor revisions" categoryrevisions are often categorized as major even though they can be completed in a matter of hours. There is a need for clarity and direction from editors rather than a simple reliance on narrow and ill-defined categories.

Failure to read paper-Perhaps the most important decision in the peer-review process is when an editor reviews referee reports and personally evaluates whether to accept it for publication, reject it, or request that it be revised (Hargens and Herting 2006). It is impossible to know whether an editor has fully read a paper; however, based on the brevity of responses often provided (e.g., in decision letters-see form letter section below) coupled with examples where comments made are barely relevant to the paper, we are led to presume that many editors do not read the papers they handle, at least not in detail. We believe that editors should read every paper that they handle twice; once at submission to evaluate suitability and once after reviews are received. Otherwise, journals could simply appoint peer review coordinators and automate the entire system simply for error checking and not scientific merit.

Lack of or excessive editing-Many editors either fail to actually edit manuscripts, or impose their personal writing style. Some journals employ copy editors and technical editors, but journal editors should still provide general and specific comments as warranted regarding format, clarity, and style of writing and presentation. Of course, some journals (particularly ones with exceptionally high impact factors; e.g., Science, Nature, TREE, BioScience) employ managing editors to essentially re-write papers after they are accepted. This level of modification is only tolerated given the prestige of publishing in said outlets. In most cases, major 
changes to writing represent the imposition of personal style rather than corrections of grammar and spelling errors. Journals that require adherence to particular stylistic conventions that are not otherwise erroneous (e.g., avoidance of split infinitives) should state these conventions explicitly in the guide to authors, and these should be enforced consistently by all members of the board of editors. Authors frequently sacrifice personal writing style to appease subjective editing requests, because the alternative option (restarting the peerreview process elsewhere) is unpalatable. Assuming that writing is grammatically correct, adjusting personal style is beyond the spirit of the peer-review process, which fundamentally serves as quality control for science. The role of editors and the peer-review process is to ensure that experimental design is sound, concepts are properly cited, and writing is error-free. The problems listed above associated with time constraints (a lack of available reviewers and editors that do not thoroughly read manuscripts) are likely exacerbated by a tendency to waste time editing writing style, rather than focusing on scientific quality.

Inability to act and think independently-When an editor reads a paper and carefully evaluates the critiques provided by referees, they have an opportunity to do more than simply accept reviews at face value. They should consider the perspective of the referees, referee experience, potential conflicts between referees and authors, and their own assessment of the paper. We have had papers rejected based on scientific problems identified by the editor despite positive reviews from referees. We accept this when justified but note that such a paper should never have been sent out for review (see above). We have also had negative reviews (all advocating for reject) where the editor recognizes a paper for what it could be and provides commentary outlining what must be changed to make it acceptable. Editors depend on peer reviewers to provide input, but at the end of the day the decision does and should lie with the editor and is based on their professional judgment and expertise.

When a paper is revised and returned to a journal, the default action should not be to immediately send it out for a secondary round of peer review. Instead, the editor should carefully evaluate the responses to editorial queries and re-evaluate the paper itself. If the entire paper needs to be overhauled with new analyses and interpretations, secondary reviews are obviously justified; however, secondary reviews are often requested when changes are rather routine. As referees, we get little personal benefit from reviewing a paper twice, and repeated reviews constrain our abilities to work on new material. On the rare occasions that we accept to provide a secondary review, we tend to do so begrudgingly, questioning the editor's inability to assess the author's responses. We suggest that if an editor has the requisite expertise to hold such a position, then we (the scientific community) should empower them to think independently when evaluating the quality of revisions and whether authors have adequately addressed referee concerns. Newton (2010) suggests that editors should avoid a "mechanical" approach to evaluating reviews and instead engage cautiously and critically with reviews and guard against bias. Obviously doing so requires that they read the paper (as above).

Critical thinking is required of editors in deciding not only whether to accept, reject, or send out a manuscript for secondary review, but in evaluating specific concerns expressed by reviewers. The quality of individual reviews is not always equal, and all comments made by reviewers are not necessarily valid or wellinformed. Editors should critically evaluate reviewer comments, and reject those that are unclear or unfounded, whether positive or negative. Editors frequently ask authors to carefully address specific reviews or comments in the revision, but rarely highlight points that may not need to be addressed. For example, we have had a referee suggest that additional data collection was necessary yet had the editor provide direction that such efforts were not required. Brief recommendations from the editor on points that may be skipped can save authors considerable efforts in responding to unimportant comments in their revision.

Reliance on form letters - Online peer-review systems can minimize editorial duties. Form letters are automatically generated based on different editorial decisions (e.g., accept, minor revisions, etc). There is ample opportunity for editors to personalize and customize such letters; however, in many cases this does not occur or only a single sentence is added to BRIEFLY note the reason for the decision. As authors we expect that, at a minimum, the editor would summarize the basis for their decision fully and clearly. They should also provide explicit instructions on the path they think authors should take. In some cases editorial comments confuse matters and add stress to authors trying to determine what path is needed. It also goes without saying that when the editors add text to the form letter that it should be void of typos and should not appear to be a rush job. Authors expect that their papers are given full and fair consideration. If an editor does not have sufficient time to do so, additional editors should be found to share the workload.

\section{Mitigating Editor Malpractice}

We have identified a number of issues that we have experienced as authors when interacting with editors of scientific journals and noted specific ways in which those issues could be addressed. Here we briefly discuss 
more general means of mitigating editorial malpractices. This is not an exhaustive list (see Aarssen and Lortie 2009, 2010 for ideas on reforming the peer-review process). Included here is the author perspective and options for authors to advocate or obtain recourse on editorial decisions with which they disagree.

On the recruitment and evaluation of editors-Editors are largely volunteers and, given the burden, there is typically not a landslide of interest in such positions. Certain journals (or publishers or professional scientific organizations) actively advertise to find editors; however, the process is often more organic, with potential editors being targeted from within either the editorial board or the associated research community. It is our assertion that the recruitment of editors should be a competitive process whereby qualifications are examined and perspectives on a variety of topics (e.g., related to ethics, journal policies, conflict resolution) are probed during an interview. Doing so would provide opportunities to identify editors with opinions or perspectives that may not be in the spirit of fairness, transparency and scientific excellence or that do not align with the journal's perspective. Relatedly, there should be some form of author-based assessment (i.e., author perspectives on the editor performance for both rejects and acceptances) and review of a subset of editorial decisions to ensure quality (e.g., editorial decisions are detailed and justified, no undue reliance on form letters). The idea here is not to retrospectively question editorial decisions but instead to identify areas for improvement and help editors develop or to replace editors that are simply not doing what is required in the job.

On the training of editors - In general, scientific editors seem to receive limited formal editorial training. Although we are unaware of any data specific to the realm of ecology and evolution, a survey of the editorsin-chief of clinical medical journals revealed that $45 \%$ of senior editors had no formal training in editing (Garrow et al. 1998). Further questions revealed that the majority (69\%) of editors believed that some form of editorial training would be useful; whereas, $26 \%$ reported that such training was not necessary. One might ask what type of training would be appropriate and how would one obtain such training? Some approaches are more organic and involve mentoring. For example, Marusic and Marusic (2001) suggest that experienced editors (particularly from international journals) have a role to play in educating other editors (including those from regional journals, especially in developing countries) in good editorial practice; however, the mechanisms for actually doing so remain unclear. Having a transition period between editors where experienced editors can mentor new ones is also a possibility, though both of those models presume that "experienced" editors actually are providing proper advice. Some larger commercial publishing houses have their own training materials (e.g., online tutorials and videos), but these lack independence from those who profit from said journals.

The Council of Scientific Editors' (CSE) mission and operations are directly related to the betterment of the scientific peer review process, primarily through providing training (e.g., via webinars and continuing education courses at their annual meeting) and resources to practicing and aspiring editors. Frankly, we had not heard of this group until we began preparing this article, despite our editorial experience. In 2004 the Committee on Publication Ethics of the World Association of Medical Editors produced a code of conduct for its editors. Although not compulsory, it provided a template regarding their responsibilities (see Godlee 2004). For ecology and evolution (or other non-medical sciences) we are unaware of a similar code, though the materials produced by the CSE contain many of these principles. Some have gone so far as to suggest competency testing for editors (e.g., Yalow 1982); however, we are unaware of any instances, at least in ecology and evolution, where this has been applied. In professions where one must maintain credentials (e.g., medicine, engineering) one could see how such training and competency testing for editors could be built into their accreditation processes, but it is more difficult to envision how this would work in the fields of ecology and evolution where there is not an overall governing board.

On the role of the author-According to Rivera (2009), editors enjoy an almost absolute power in deciding "what gets published" and are rarely accountable. Indeed, most authors regard editorial decisions as final (Simon et al. 1986; Warren 2000) and simply walk away when conflicts arise. Ray (2002) discussed the role of journal editors and the ability of authors to challenge their perspectives. Using the example of an appeal process in the judicial system, Ray (2002) notes that there should be a mechanism for authors to formally question editorial decisions. One of the reasons why most authors accept editorial decisions as gospel is the fear of upsetting senior scientists in their field, and the potential consequences for future submissions. Relatedly, there is the belief that editors would never change their mind. Quite simply, there is no independent appeal process. The reality is that it is possible to question editorial decisions (Simon et al. 1986; Warren 2000) and we have done so (successfully and unsuccessfully) on rare occasion. We are not suggesting that the default for every rejection should be a missive suggesting that they reconsider their decision; however, if the author feels that the process was in some way unfair or that the 


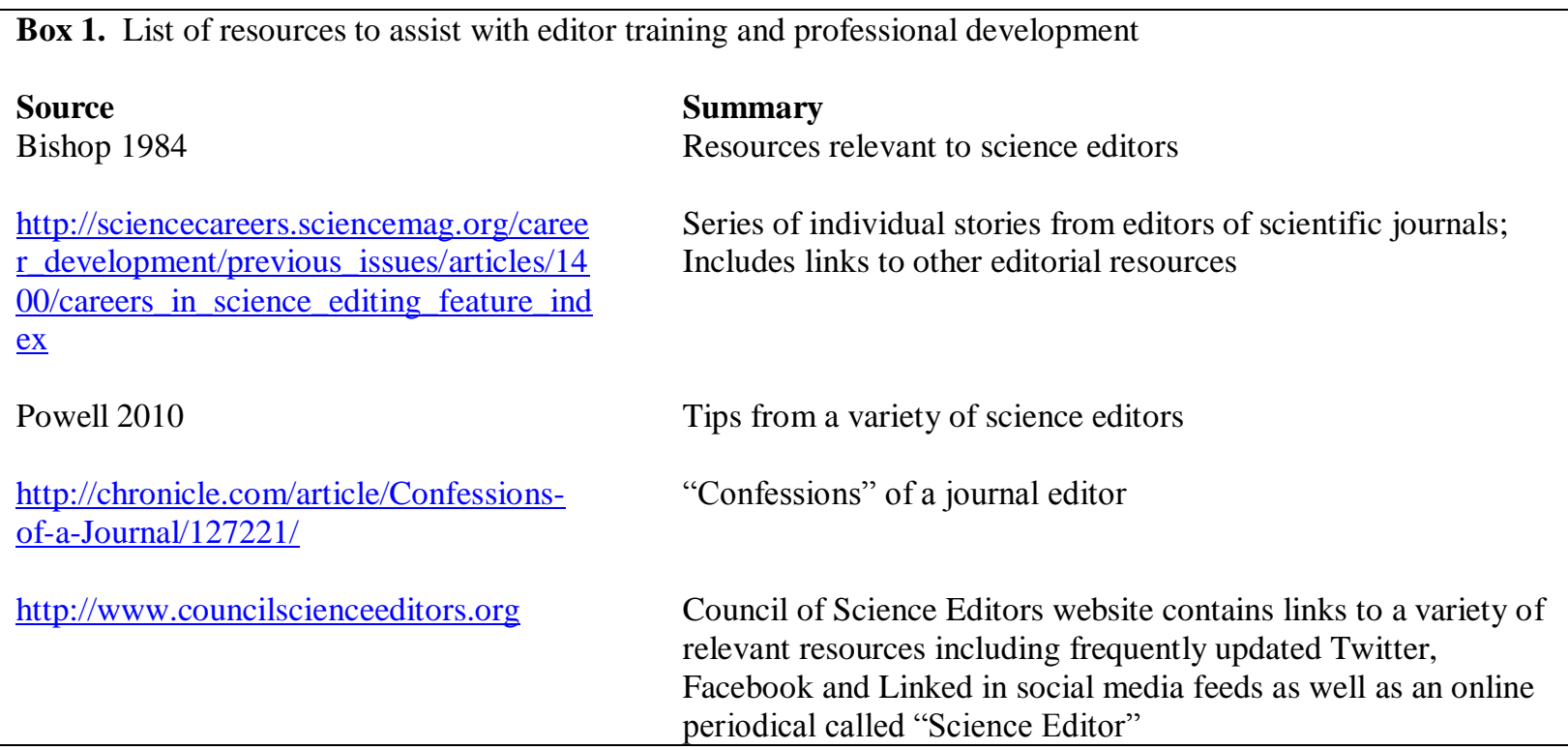

editor (or referees) missed an important point or were in error, it is reasonable to adopt a strong authorial voice in requesting that the decision be revisited (Bedeian 2004). A study of 74 authors who requested reconsideration of manuscripts rejected by the American Sociological Review over a 4 -year period revealed that $13 \%$ were regarded as having valid complaints and thus succeeded in having their work eventually accepted for publication in that journal (Simon et al. 1986). Just as scientific papers can contain mistakes and erroneous information or concepts, so too can peer reviews or editorial perspectives. Sen (2012) describes a new experimental method (termed "rebound peer review") involving partially-blinded and open peer review used by the journal Antioxidants and Redox Signalling intended to provide recourse for authors who felt that their work had been rejected unfairly.

As an author, it is also important to stay true to your own vision for the paper (Frey 2003). At times, heavyhanded editorial input would suggest reframing the paper or rewriting it in a manner with which you are not comfortable (Roth 2002). When revising a paper, we essentially question how much of the process is about genuinely trying to improve the paper rather than simply doing what is needed to appease the editor. We are not suggesting that all editorial input be dismissed, but we carefully weigh all direction from referees and editors, trying to understand what led to their conclusions (e.g., did we miss something, where can we improve clarity?). Herxmier (1989) suggests that one problem for authors is not knowing what editors want in terms of submissions and in how they should respond to editorial queries and criticisms. We submit that since the Herxmier (1989) opinion was published, the internet has made information (e.g., detailed guides to authors, links to examples, online tutorials) specific to how to format content more available. Yet, there is still a lack of clarity on precisely what will lead editors to determine which papers are a good fit with a given journal or how to interpret editor comments and decisions. As noted above, use of form letters does appear to add to this problem.

\section{Conclusion}

As noted by the Council of Science Editors, treating all authors with fairness, courtesy, objectivity, honesty, and transparency is one of the roles of editors. There are indeed many other roles but for the purpose of this paper, we have dwelled on those aspects which relate to the behaviour of editors. Being an editor for a scientific journal is a largely thankless task and although there is prestige associated with such positions, there are also often costs to one's research program, student mentoring, and time with family and friends. The reality is that authors and referees are also "volunteers" in the publishing world (Lortie 2011) and they have been subject to much critique (e.g., Resnik 2011; Ploegh 2011). Similarly, publishers (Taylor 2012) and various publishing and peer-review practices (Aarssen and Lortie 2009, 2010; Bornmann 2011) have also received much attention. Conversely, editor behaviour seems to be rarely considered despite significant heterogeneity in perspectives and behaviours (Wilkes and Kravitz 1995), even within a given journal. As we embark on new editorial activities, we have spent much time reflecting on our experiences and thinking about how we can best serve authors and the scientific community. We have determined that we need to learn more and would benefit from more formal training. We were pleased to find out that such resources do exist (See Box 1), though no one has referred us to them in our previous editorial 
roles. We trust that this paper will stimulate discussion within the community and introspection by editors regarding what can be done to address some of the issues, inconveniences and inconsistencies noted above such that editor malpractice can be reduced or eliminated. Beyond making the process less frustrating, it is our hope that doing so will also improve the peer-review process and scientific outputs. Do you want to become an editor?

\section{Acknowledgements}

Cooke is supported by NSERC and the Canada Research Chairs Program. Lapointe is supported by the Ontario Ministry of Research and Innovation. We thank Keith Stamplecoskie for formatting the manuscript and Dr. Chris Lortie for providing comments to improve the document. We also thank the many excellent editors which have collectively assisted us with improving our writing and learning about the editorial process. Specifically, Cooke wishes to recognize Dr. Mike Hansen and Dr. Dennis Devries for providing exceptional editorial interactions early in his career and helping to define good editorial practice.

\section{Special Issue Editors}

Christopher Lortie - lortie@yorku.ca

York University

Jarrett E. Byrnes - byrnes@msi.ucsb.edu

University of Massachusetts Boston

\section{References}

Aarssen, L.W. 2012. Are peer-review filters optimal for the progress of science in ecology and evolution? Ideas in Ecology and Evolution 5: 9-12. CrossRef

Aarssen, L.W., and C.J. Lortie. 2009. Ending elitism in peer-review publication. Ideas in Ecology and Evolution 2: 18-20. CrossRef

Aarssen, L.W., and C.J. Lortie. 2010. Ideas for judging merit in manuscripts and authors. Ideas in Ecology and Evolution 3: 28-34. CrossRef

Bedeian, A.G. 2004. Peer Review and the Social Construction of Knowledge in the Management Discipline. Academy of Management Learning \& Education 3: 198-216. CrossRef

Bishop, C.T. 1984. How to edit a scientific journal. ISI Press, Philadelphia, PA.

Bornmann, L. 2011. Scientific peer review. Annual Review of Information Science and Technology, 45: 199-245.

Campanario, J.M. 1996. The competition for journal space among referees, editors, and other authors and its influence on journal's impact factors. Journal of the American Society for Information Science 47: 184-192.

Crandall, R. 1986. Peer review: improving editorial procedures. BioScience 36: 607-609. CrossRef

Crane, D. 1967. The gatekeepers of science: Some factors affecting the selection of articles for scientific journals. American Sociologist 2: 195-201.

Donaldson, M.R., Hanson, K.C., Hasler, C.T., Clark, T.D., Hinch, S.G., and S.J. Cooke. 2010. Injecting youth into peer-review to increase its sustainability: a case study of ecology journals. Ideas in Ecology and Evolution 3: 1-7. CrossRef

Frey, B.S. 2003. Publishing as prostitution?-Choosing between one's own ideas and academic success. Public Choice 116: 205-223. CrossRef

Garrow, J., Butterfield, M., Marshall, J., and A. Williamson. 1998. The reported training and experience of editors in chief of specialist clinical medical journals. JAMA: The Journal of the American Medical Association, 280: 286-287. CrossRef

Gilbert, G.N. 1976. The transformation of research findings into scientific knowledge. Social Studies of Science 6: 281-306. CrossRef

Godlee, F. 2004. Dealing with editorial misconduct. New code of conduct for editors is a first step in self regulation. BMJ 329: 1301-1302. CrossRef

Hargens, L.L., and Herting, J.R. 2006. Analyzing the association between referees' recommendations and editors' decisions. Scientometrics, 67: 15-26. CrossRef

Herxheimer, A. 1989. Make scientific journals more responsive-and responsible. The Scientist 3: 9-11.

Justice, A.C., Berlin, J.A. Fletcher, S.W., Fletcher, R.H., and S.N. Goodman. 1994. Do readers and peer reviewers agree on manuscript quality? JAMA: The Journal of the American Medical Association 272: 117-119. CrossRef

Krell, F.T. 2010. Should editors influence journal impact factors? Learned Publishing 23: 59-62. CrossRef

Lortie, C.J. 2011. Money for nothing and your referees for free. Ideas in Ecology and Evolution 4: 43-47. CrossRef

Lundberg, G.D., Paul, M.C., and H. Fritz. 1998. A comparison of the opinions of experts and readers as to what topics a general medical journal (JAMA) should address. JAMA: The Journal of the American Medical Association 280: 288-290. CrossRef

Marusic, A., Katavic, V., and M. Marusic. 2007. Role of editors and journals in detecting and preventing scientific misconduct: strengths, weaknesses, opportunities, and threats. Medicine and Law 26: 545-66.

Marusic, M., and A. Marusic. 2001. Good editorial practice: Editors as educators. Croatian Medical Journal 42: 113-120. 
Newton, D.P. 2010. Quality and peer review of research: an adjudicating role for editors. Accountability in Research 17: 130-145. CrossRef

Ploegh, H. 2011. End the wasteful tyranny of reviewer experiments. Nature 472: 391. CrossRef

Powell, K. 2010. Gatekeeper's burden. Nature 464: 800-801. CrossRef

Ray, J.G. 2002. Judging the judges: the role of journal editors. Quarterly Journal of Medicine 95: 769-774. CrossRef

Resnik, D.B. 2011. A Troubled Tradition. American Scientist 99: 24-27.

Rivera, H. 2009. Editors' malpractice: forward submitted letters (to the concerned authors), then reject them, Accountability in Research 16: 331333. CrossRef

Robertson, M. 2009. What are journals for? Journal of Biology 8: 1. CrossRef

Roediger, H. L. 1987. The role of journal editors in the scientific process. Pages 222-252 in Jackson, D.N. and J. P. Rushton, editors. Scientific excellence: Origins and assessment. Sage Publications, Newbury Park, NJ.

Roland, M.C. 2009. Quality and integrity in scientific writing: prerequisites for quality in science communication. Journal of Science Communication, 8: A04.

Roth, W.M. 2002. Editorial power/authorial suffering. Research in Science Education 32: 215-240. CrossRef

Schäfer, R.B., Cooke, S.J., Arlinghaus, R., Bonada, N., Brischoux, F., Casper, A.F., Catford, J.A., and V. Rolland. 2011. Early career researchers' perspectives on the current and future state of the scientific publication process in ecology. Freshwater Biology 56: 2405-2412. CrossRef
Sen, C.K. 2012. Rebound peer review: a viable recourse for aggrieved authors? Antioxidant Redox and Signaling 16: 293-296. CrossRef

Shamoo, A.E. 1994. Editors, Peer Reviews, and Ethics. AAAS Perspectives 14: 4-5.

Simon, R.J., Bakanic, V., and C. McPhail. 1986. Who complains to journal editors and what happens? Sociological Inquiry 56: 259-271. CrossRef

Smith, R. 2006. Peer review: a flawed process at the heart of science and journals, Journal of the Royal Society of Medicine 99: 178-182. CrossRef

Taylor, M. 2012. Academic publishers have become the enemies of science. Gaurdian, UK. www.guardian.co.uk, Monday 16 January 2012.

Wardle, D. 2012. On plummeting manuscript acceptance rates by the main ecological journals and the progress of ecology. Ideas in Ecology and Evolution 5: $13-15$.

Warren, M.G. 2000. Reading reviews, suffering rejection, and advocating for your paper. Pages 169186 in R.J. Sternberg, editor. Guide to publishing in psychology journals. Cambridge University Press, Cambridge, United Kingdom. CrossRef

Wilkes, M.S., and R.L. Kravitz. 1995. Policies, practices, and attitudes of North American medical journal editors. Journal of General Internal Medicine 10: 443-50. $\underline{\text { CrossRef }}$

Yalow, R. S. 1982. Competency testing for reviewers and editors. Behavioral and Brain Sciences 5: 244245. CrossRef

Zanna, M.P. 1992. My life as a dog (I mean editor). Personality and Social Psychology Bulletin 18: 485488. CrossRef 